\title{
In vivo study of follicular statistics in Red Chittagong Cattle of Bangladesh
}

\author{
GK Deb ${ }^{1} *$, MA Kabir ${ }^{1}$, MFH Miraz ${ }^{1}$, SMJ Hossain ${ }^{1}$, MF Afroz ${ }^{1}$, TN Nahar ${ }^{1}$ and MK Mostofa ${ }^{2}$
}

${ }^{1}$ Bangladesh Livestock Research Institute, Savar, Dhaka $1341 ;{ }^{2}$ Upazilla Livestock Officer, Department of Livestock Services, Savar, Dhaka, Bangladesh

\begin{abstract}
The objective of this research was to generate baseline information on follicular statistics of Red Chittagong Cattle (RCC).Ten heifers and ten regular breeder RCC cows were selected randomly from BLRI Research Herd. The ovary was grasped by inserting left hand through the rectum and the follicles were visualized by inserting a sectorial probe through the vagina. Ovarian follicles were visualized and recorded by counting on the screen of ultrasonography machine. All visible follicles $(>2.0 \mathrm{~mm})$ were counted and graded as small $(<3.0 \mathrm{~mm})$, medium $(3.0$ to $8.0 \mathrm{~mm})$ and large $(>8.0 \mathrm{~mm})$. The follicles were measured 3 times at a 3 -day interval period without considering the stage of the reproductive cycle of the experimental animals. During this experiment, a total of 137 follicles (66 in Heifers and 71in cows) were observed from 10 heifers and 10 cows. The corpus luteum was observed either in the left or right ovary of $25.0 \%$ heifers and $35.0 \%$ cows. In heifer, $40.91,45.45$ and $13.64 \%$ of the observed follicles were belonged to small, medium and large groups, respectively. The percentage of small, medium and large follicles in the cow ovaries were 54.93, 39.44 and 5.63\% accordingly. The number of follicles in an ovary did not vary $(P>0.05)$ between right and left ovary of a heifer or cow. The diameter of the largest follicle on the ovary was smaller $(P<0.05)$ in heifer $(9.43 \pm 0.34 \mathrm{~mm})$ compared to cow $(11.2 \pm 0.73 \mathrm{~mm})$. This information will be helpful during aspiration of ovarian follicle from donor cows.
\end{abstract}

Key words: dairy goat, body weight, milk yield, reproductive performance

\section{Introduction}

The ultrasound-guided transvaginal ovum pick-up (OPU) based in vitro embryo production (IVP) represents one of the major assisted reproductive technology used for faster multiplication of high yielding dairy and beef cows in short time. This technique can be used repeatedly on live animals for collection of large number of oocytes from individual donors of all ages ( 2 months old calves to very old cows), unknown fertility, various physiological phases of reproduction and even pregnant animals (up to 3 months), without any side effects on donor's reproductive performance (Boni et al., 1996). The establishment of oocyte aspiration from donor cow requires baseline information on biometry of female genital tractand ovarian follicular dynamics. The knowledge of biometrical status of female genital tract is essential to perform artificial insemination, pregnancy diagnosis, dealing with the infertility problems, in vivo and in vitro manipulation of folliculogenesis and embryo transfer (Kumar et al., 2004; Lucy et al., 1992).
The number of oocytes recovered during an OPU session depends on the number of antral follicles available in the ovary for aspiration (Bols et al., 1998). The number of oocytes recovered during an OPU session affects subsequent embryo development (Deb et al., 2011). However, the research data on follicular statistics of Red Chittagong cattle(RCC) are scanty. The RCC is an indigenous cattle breed of Bangladesh, which is tropically well adapted and suitable for the medium to small farmers. Because, the RCC is well known for its higher conception rate, short post-partum heat period, higher milk fat content, resistant to common local diseases and cost effectiveness (Halim et. al., 2010).Considering these facts, the present research program was designed to generate baseline information on follicular statistics of RCC.

\section{Materials and Methods}

Ten heifers and ten regular breeder RCC cows were selected randomly from BLRI Cattle Research Herd. The average body weight of the selected animals was $139.03 \pm 0.54 \mathrm{~kg}$ for heifers and $151.07 \pm 0.23 \mathrm{~kg}$ for cows. To develop

*Corresponding author: debgk2003@yahoo.com 
expertise on manipulation of ovarian follicular statistics, initially four culled RCC cows were routinely evaluated by rectal palpation for couple of months. Later ovarian follicles were visualized by ultrasonography machine (Dus $60 \mathrm{Vet}$, Edan). Before visualization of ovarian follicles, the feces were removed from the rectum and the surrounding areas of vulva and rectum were swabbed with disinfectant to prevent infection in the reproductive tract. The ovary was grasped by inserting left hand through the rectum and the follicles were visualized by inserting a sectorial probe through the vagina. Before inserting the probe, it was disinfected by swabbing with $70 \%$ alcohol. Follicle numbers were recorded by counting on the screen of ultrasonography machine. The diameters of follicles were recorded by measuring length and breadth of each follicle on the screen (Figure 1 ). All visible follicles $(>2.0$ $\mathrm{mm}$ ) were counted and graded as small $(<3.0$ $\mathrm{mm})$, medium ( 3.0 to $8.0 \mathrm{~mm}$ ) and large $(>8.0$ $\mathrm{mm}$ ). The machine only can measure follicles of greater than $2.0 \mathrm{~mm}$. The follicles were measured 3 times at a 3-day interval period without considering the stage of the reproductive cycle of the experimental animals. Data were analyzed following one way ANOVA procedure and mean differences were tested by Duncuns multiple range test using 'SPSS-11.5' statistical package.

\section{Results}

During this experiment, a total of 137 follicles were observed from 10 heifers and 10 cows. The corpus luteum was observed either in the left or right ovary of $25.0 \%$ heifers and $35.0 \%$ cows (Table 1). Among the total follicles, 66 follicles (36 in the right and 30 in the left ovary) were studied in heifers and 71 in cows (38 in the right and 33 in the left ovary). In heifer, 40.91, 45.45 and $13.64 \%$ of the studied follicles were belonged to small, medium and large groups, respectively. The percentages of small, medium and large follicles in the cow ovaries were 54.93, 39.44 and $5.63 \%$ accordingly. The average numbers of follicles according to their size and ovarian positions were given in Table 2. Numbers of small follicles per ovary were higher in cow than heifers $(P<0.05)$. The number of follicles in an ovary did not vary $(P>0.05)$ between right and left ovary of a heifer or cow. However, in general cow ovary possesses higher number of small $(P<0.05)$ and medium $(P<0.05)$ follicles than ovary of aheifer (Table 3). No differences were observed for large follicle and total follicle numbers between a cow and heifer ovary $(P>0.05)$. The diameter of the largest follicle on the ovary was smaller $(P<0.05)$ in heifer $(9.43 \pm 0.34 \mathrm{~mm})$ compared to cow $(11.2 \pm 0.73 \mathrm{~mm})$.

\section{Discussion}

Ovum pick-up (OPU) based in vitro embryo production technology is widely adopted for multiplication of high yielding cows in many countries. Understanding of ovarian follicular population is required for adoption of OPU technology in cattle breeding. During this study, the ovarian follicular population of RCC cattle was studied using ultasonography system. During this study period, various sized follicles were observed in the ovary of heifers and cows (Table 1). Total number of follicles per ovary did not vary between RCC heifer and cow. This result are not in consistent with the findings of Sakhong et al. (2011). They reported that Native Thai cattle heifer possessed higher number of follicles (6.296.69) than cow $(4.0-5.0 \mathrm{~mm})$. They also reported that greater numbers of small follicles in heifers than in cows. Follicle numbers and sizes continuously and considerably oscillates during the cycle (Adams et al., 1992) due to wave-like development pattern in cattle (Knopf et al., 1989; Savio et al., 1988; Rhodes et al., 1995).

Table 1. Presence of ovarian follicles of Red Chittagong cattle

\begin{tabular}{|c|c|c|c|}
\hline Parameters & Heifer & Cows & Sig \\
\hline Numbers of total follicles observed & 66 & 71 & - \\
\hline Small follicle number per ovary (\%) & $1.35^{\mathrm{b}} \pm 0.67(40.91)$ & $1.95^{\mathrm{a}} \pm 1.57(54.93)$ & $P<0.01$ \\
\hline Medium follicle number per ovary (\%) & $1.50^{c} \pm 0.94 \quad(45.45)$ & $1.40^{d} \pm 0.19(39.44)$ & $P<0.05$ \\
\hline Large follicle number per ovary (\%) & $0.45 \pm 0.39(13.64)$ & $0.20 \pm 0.07(5.63)$ & NS \\
\hline Total follicle number per ovary (\%) & $3.30 \pm 0.25$ & $3.55 \pm 0.35$ & NS \\
\hline$\%$ Corpus luteum in ovary & 25.0 & 35.0 & NS \\
\hline $\begin{array}{l}\text { Diameter of largest follicle in the } \\
\text { ovary (Mean } \pm \text { SE in } \mathrm{mm} \text { ) }\end{array}$ & $9.43^{b} \pm 0.34$ & $11.2^{\mathrm{a}} \pm 0.73$ & $P<0.05$ \\
\hline
\end{tabular}


Table 2. Ovarian follicular statistics of heifers and cows of Red Chittagong Cattle breed

\begin{tabular}{lrrrrrr}
\hline \multirow{2}{*}{$\begin{array}{c}\text { Follicle per } \\
\text { ovary }\end{array}$} & \multicolumn{3}{c}{ Heifer (Mean \pm SE in mm) } & \multicolumn{2}{c}{ Cow (Mean \pm SE in mm) } \\
\cline { 2 - 7 } & Right ovary & \multicolumn{1}{c}{ Left ovary } & \multicolumn{1}{c}{ Overall } & Right ovary & \multicolumn{1}{c}{ Left ovary } & \multicolumn{1}{c}{ Overall } \\
\hline Small & $1.25^{\mathrm{b}} \pm 0.28$ & $1.45^{\mathrm{a}} \pm 0.20$ & $1.35 \pm 0.17$ & $2.30^{\mathrm{a}} \pm 0.50$ & $1.60^{\mathrm{a}} \pm 0.41$ & $1.95 \pm 1.57$ \\
Medium & $1.75^{\mathrm{a}} \pm 0.31$ & $1.25^{\mathrm{a}} \pm 0.29$ & $1.50 \pm 0.21$ & $1.40^{\mathrm{a}} \pm 0.24$ & $1.40^{\mathrm{a}} \pm 0.27$ & $1.40 \pm 0.19$ \\
Large & $0.60^{\mathrm{b}} \pm 0.15$ & $0.30^{\mathrm{b}} \pm 0.11$ & $0.45 \pm 0.10$ & $0.10^{\mathrm{b}} \pm 0.08$ & $0.30^{\mathrm{b}} \pm 0.08$ & $0.20 \pm .07$ \\
Significance & $\mathrm{P}<0.05$ & $\mathrm{P}<0.01$ & & $\mathrm{P}<0.01$ & $\mathrm{P}<0.01$ & \\
$\begin{array}{l}\text { Number of } \\
\text { follicles per }\end{array}$ & $3.60 \pm 0.30$ & $3.00 \pm 0.46$ & $3.30 \pm 0.25$ & $3.80 \pm 0.42$ & $3.30 \pm 0.58$ & $3.55 \pm 0.35$ \\
ovary & & & & & & \\
\hline
\end{tabular}

${ }^{\mathrm{a}-\mathrm{b}}$ Within a column, means without common superscripts differ $\mathrm{P}<0.05$ ).

Therefore, presence of various sized follicles in the ovary is an indicator of ovarian functionality in bovine. Presence of various sized follicles in RCC heifer/cow ovaries are in agreement with previous report (Adams et al., 1992). Large number of small follicles in RCC cow ovary than heifer might be associated with time period of ovarian cycle. In general majority of the follicles were small to medium in both heifers and cows. Presence of large number of small to medium size follicle is good for ovum pick up. The bovine ovary possesses large numbers of small follicular reserve (McDonald, 1980). No differences ( $P>0.05$ ) were also observed between right and left ovary for total follicle numbers in both RCC heifer $(3.60 \pm 0.30$ vs. $3.00 \pm 0.46)$ and cow $(3.80 \pm 0.42$ vs. $3.30 \pm 0.58)$. Morrow et al., (1968) observed that the right ovary was more active than the left one.The diameter of the largest follicle of each ovary was recorded and average diameters were found smaller $(P<0.05)$ in the heifer compared to the cow. This results are in agreement with Sakhong et al. (2011). Carvalho et al. (2008) founded maximum diameter of the dominant follicle of Bos indicus heifers was $9.5 \pm 0.5 \mathrm{~mm}$, which was similar to RCC heifer.

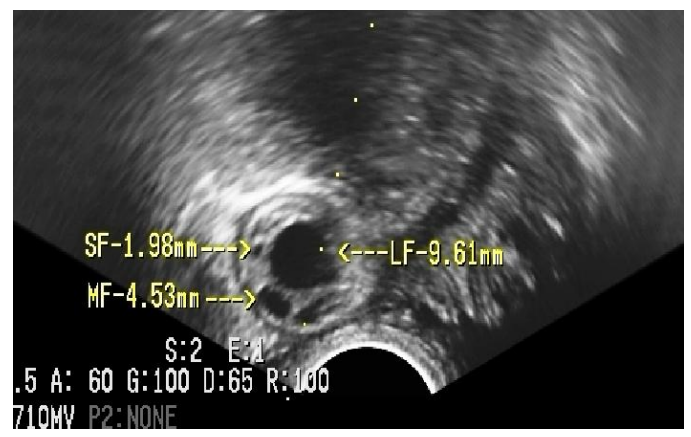

Figure 1. Ultrasonographic visualization of ovarian follicle in Red Chittagong Cow. LF= Large follicle, $\mathrm{MF}=$ Medium follicle and $\mathrm{SF}=\mathrm{Small}$ follicle

\section{Conflicts of interest}

We, the affiliated authors whose names are mentioned in the manuscript, hereby, clearly certify that, we have NO affiliations with or involvement in any organization or entity with any financial interest or non-financial interests in the subject matter or materials discussed in this manuscript.

\section{Conclusion}

In conclusion, the present study developed base line information on ovarian follicular statistics of RCC heifers and cows. Different types of follicle are evenly distributed in both ovaries, although large no of follicle and follicular diameter are higher in right ovaries. This information will be helpful during aspiration of oocytes from donor cows.

\section{References}

Adams GP, Matteri RL, Kastelic JP, $\mathrm{Ko} J \mathrm{CH}$, Ginther OJ (1992). Association between surges of follicle stimulating hormone and the emergence of follicular waves in heifers. Journal of Reproduction and Fertility, 94: 177-188.

Blondin $\mathrm{P}$, Vigneault $\mathrm{C}$, Nivet $\mathrm{AL}$, Sirard $\mathrm{MA}$ (2012). Improving oocyte quality in cows and heifers - What have we learned so far? Animal Reproduction, 9 (3):281-289.

Bols PE, YsebaertMT, Lein A, CorynM, van Soom A, KruifA de (1998). Effects of long-term treatment with bovine somatotropin on follicular dynamics and subsequent oocyte and blastocyst yield in an OPU-IVF Program. Theriogenology, 49:983-995.

Boni R, Roveillo S, Zicarelli L(1996). Repeated ovum pick up in Italian Mediterranean buffalo cows. Theriogenology, 46: 899909.

Carvalho JBP, Carvalho NAT, Reis EL, Nichi M, Souza AH , Baruselli PS(2008). Effect of 
early luteolysis in progesterone-based timed AI protocols in Bos indicus, Bos indicus Bos taurus, and Bos taurus heifers. Theriogenology, 69: 167-175.

Deb GK, Khan MYA, Dey SR, Khondoker MAMY, Rahman MM. (2012). Establishment of in vitro embryo production system with slaughterhouse ovaries. Paper presented in the annual research review workshop held at Bangladesh Livestock Research Institute, Savar, Dhaka in 24-25.

Deb GK., Jin JI, Kwon TH, Choi BH, Cho SJ, Bang JI, Dey SR, Ch IR, Kong IK (2011).Improved blastocyst development of single cow OPU-derived presumptive zygotes by group culture with agaroseembedded helper embryos. Reproduction Biology and Endocrinology, 9:121.

Halim MA, KashemMA, Ahmed JUand HossainM(2010).Economic analysis of Red Chittagong Cattle farming system in someselected areas of Chittagong district.Journal of Bangladesh Agricultural University, 8(2): 271-276.

Hopper HW, Silcox RW, Byerley DJ, Kiser TE (1993). Follicular development in prepubertal heifers. Animal Reproduction Science, 31:7-12.
Kanitz W (2001). Comparative aspects of folicular development, follicular and oocyte maturation and ovulation in cattle and pigs. Arch Animal Breeding, 44: 923.

Kumar S, Ahmed FA, BhadwalMS (2004). Biometry of female genitalia of Murrah buffalo (Bubalus bubalis). Indian Journal of Animal Reproduction, 25:143-145.

Lucy MC, SavioJD, BadingaL, De La Sota RL, WW Thatcher (1992). Factors that affect ovarian follicular dynamics in cattle. Journal of Animal Science, 70:3615-3626.

McDonald (1980). Veterinary Endocrinology and Reproduction. Lea and Febiger, Philadalphia, 274-398.

Morrow DA, Roberts SJ, Entee KM (1968). Latent effects of pregnancy on postpartum ovarian activity in dairy cattle. Journal of Animal Science, 27: 1408-1411.

Sakhong D, Vongpralub $\mathrm{T}$, Katawatin S, Sirisathien S (2011). Ovarian Follicular Patterns and Hormone Profile in Thai Native Cattle (Bos indicus). Thai Journal of Veterinary Medcine, 41(4): 439-447. 